\title{
Effect of Microtubule-associated Protein MHP1 on Microtubule Assembly and Cell Cycle Progression in Saccharomyces cerevisiae
}

\author{
Irmgard Irminger-Finger* and Nathalie Mathis \\ Division of Oncology, University of Geneva, CMU, 1, rue Michel-Servet, 1211 Geneva 4, Switzerland
}

Key words: cell cycle/microtubule assembly/microtubule-associated protein/microtubule dynamics/tubulin

\begin{abstract}
Microtubule-associated proteins (MAPs) promote the assembly of microtubules from purified tubulin in vitro. In order to establish a model system for the investigation of the role of MAPs in microtubule assembly in vivo, we have generated Saccharomyces cerevisiae strains that permit the modulation of the expression levels of MHP1 (MAP-Homologous Protein 1) and of the $\alpha$ and $\beta$-tubulin genes. Simultaneous overexpression of $\alpha$ and $\beta$ tubulin results in the accumulation of long aberrant microtubules in interphase, a similar phenotype as was observed in cells overexpressing MHP1. We demonstrate that overexpression of MHP1 in asynchronously growing yeast cultures leads to cell cycle arrest in G2. In cells that overexpress MHP1 and the tubulin genes, a suppression of both the MHP1 and the tubulin overexpression phenotypes can be observed. Progressive induction of $\alpha$ and $\beta$ tubulin overexpression and constitutive overexpression of MHP1 lead to the formation of long cytoplasmic microtubules more frequently than observed in cells overproducing tubulin or Mhp1p individually and the increased microtubule polymerization could be correlated with the increase of $\alpha$ and $\beta$ tubulin expression. However, the overexpression of MHP1 did not alter the phenotypes of individual overexpression of $\alpha$ or $\beta$-tubulin. These data indicate that Mhp1p not only stabilizes microtubules but promotes microtubule assembly in vivo, and suggest that the role of other mammalian MAPs in the promotion of microtubule assembly could be tested in this yeast system.
\end{abstract}

Microtubules (MTs) in vivo are highly dynamic polymers and their turnover appears to be regulated during the cell cycle. MT dynamics are characterized by distinct parameters governing growth and shrinking in higher eucaryotes. In vivo these rates determine the fraction of tubulin present as polymer or dimer. There is growing evidence that MT-associated proteins (MAPs) play a key role in the regulation of the rate of MT turnover during the cell cycle by influencing growth rate, catastrophe rate, and rescue frequency (22).

Functional studies on the regulation of MT dynamics in vitro have been carried out with neural MAPs (10, 20,28 ) and ubiquitously expressed MAP4 type proteins (25). The addition of MAPs produces a net increase in polymer formation, mainly by decreasing the turnover rate, suppressing catastrophes, and increasing rescues $(8,13)$. As a result the stabilization of MTs can be observed. The phosphorylation of MAPs leads to reduced binding to MTs and, as a consequence, to a reduction of the MT stabilizing activity of MAPs. Therefore the phosphorylation of MAPs can be considered as a mechanism for the modulation of polymer turnover.

\footnotetext{
* To whom correspondence should be addressed.

Tel: +41-22-7025813, Fax: +41-22-7025819

E-mail: iirminger@cmu.unige.ch
}

In vivo and in vitro studies on the specific role of MAPs in MT assembly have yielded mixed results. Transfection of MAP2 and tau into fibroblasts resulted in increased MT stability and assembly $(11,21)$, but overexpression of MAP4, 205K MAP, and tau in $\mathrm{CHO}$ cells led to the formation of MT bundles but not to an increase of MT assembly (4). The injection of monoclonal antibodies against the HeLa MAP4 led to cell cycle arrest during mitosis (16), however, the injection of polyclonal antibodies against the MT binding domain of MAP4 produced no observable phenotype (23).

MT dynamics also depend on the total tubulin concentration in the cell. The correlation of total tubulin concentration and MT formation has been studied in vivo in the yeast Saccharomyces cerevisiae that possesses only one essential $\alpha$ and one $\beta$-tubulin gene (6, 32 ). The critical concentration for yeast tubulin polymerization is significantly lower than that for brain tubulin, and the dynamic properties of MTs in Saccharomyces cerevisiae reflect the particular requirements of the yeast cell (9). Consequently, the yeast cell is sensitive to the tubulin gene dosage and excess tubulin is lethal to the cell $(7,17)$.

While the individual overexpression of $\beta$-tubulin is toxic to the cells, the overexpression of $\alpha$-tubulin has 
little effect on viability $(6,7)$. When an excess of $\beta$-tubulin over $\alpha$-tubulin is produced in yeast, MTs disassemble a short time after the induction of $\beta$-tubulin overexpression (17). The simultaneous overexpression of $\alpha$ and $\beta$-tubulin partially compensates the lethality caused by the overexpression of $\beta$-tubulin. A similar compensation of the excess $\beta$-tubulin can be observed with the overexpression of RBL2, encoding a protein involved in tubulin folding rather than in polymer assembly (2).

The MHP1 gene of Saccharomyces cerevisiae, encoding a MAP that shares features with MAP4 type proteins, is essential in yeast and required for MT function (14). MTs are sparsely formed in the absence of Mhp1p indicating a role of Mhp1p in the formation and/or stabilization of MTs. In cells overexpressing the entire MHP1 gene, longer and denser MT fibers can be observed during interphase than in cells with wild type levels of Mhp1p. Here we report that the overexpression of MHP1 results in cell cycle arrest during G2 and inhibition of the formation of mitotic MTs, presumably due to the hyperstabilization of interphase MTs. We have also studied MHP1 overexpression in cells that simultaneously overexpress both $\alpha$ and $\beta$-tubulin or either $\alpha$ and $\beta$-tubulin individually, and we demonstrate that Mhp1p not only stabilizes preformed MTs but promotes the formation of excess MT fibers under conditions of elevated tubulin expression.

\section{MATERIALS AND METHODS}

\section{Construction of overexpression plasmids and strains}

MHP1 overexpression strain Y509 was described previously (14). The YEP-MHP1 plasmid carrying the URA3 ${ }^{+}$marker was transformed into FLT12 cells (6) which contain TUB1 and TUB2 on a $2 \mu$ plasmid with the selectable marker $\mathrm{LEU}^{+}{ }^{+} \mathrm{Leu}^{+}, \mathrm{ura}^{+}$transformants FLT13 were selected and analyzed for protein expression from the three genes. FLT12 cells were grown similarly but selection was for $\mathrm{leu}^{+}$only. Y509 cells were grown continuously in ura ${ }^{-}$medium for Western blot analyses of protein extracts and immunofluorescence analyses. FUT1 and FLT2 cells that express TUB1 or TUB2, respectively, under the control of the GAL10 promoter, were transformed with YEP-MHP1 and designated FUT4 and FLT4, respectively.

\section{Immunofluorescence microscopy}

Y509 cells were grown for two to three days in selective medium to reach an $\mathrm{OD}_{600}$ of 0.5 . FLT12 and FLT13 cells were grown overnight in glucose containing selective medium, centrifuged and resuspended in galactose containing selective medium. Yeast cells were harvested for immunofluorescence, fixed and digested as described (18). Cells were mounted on coverslips and MTs were visualized with monoclonal anti$\alpha$-tubulin YOL1/34 (19) or with monoclonal anti- $\beta$-tubulin antibodies (Boehringer). Secondary antibodies were applied as Rhodamine conjugates (Sochochim) in a 1:20 dilution, and DNA was visualized with DAPI staining.

\section{Flow cytometry}

Progression of cells through S phase and mitosis was monitored by measuring the DNA content of asynchronously growing cell cultures by FACS. Overnight cultures of different yeast strains were harvested, fixed with formaldehyde, digested with zymoliase as described for immunofluorescence analysis, and treated with RNase $(10 \mu \mathrm{g} / \mathrm{ml})$ for $30 \mathrm{~min}$. DNA staining was performed with $1 \mu \mathrm{g} / \mathrm{ml}$ propidium iodide in staining buff-er (Triton X-100, 0.1\%; $\mathrm{MgCl}_{2}, 2 \mathrm{mM} ; \mathrm{NaCl}$, $0.1 \mathrm{M}$; Pipes buff-er $10 \mathrm{mM}, \mathrm{pH} 6.8$ ) for at least $30 \mathrm{~min}$ at $\mathrm{RT}$, prior to measurement. Cell fluorescence was measured with laser excitation of $488 \mathrm{~nm}$. Data acquisition and analyses were carried out with a Beckton/Dickinson flow cytometer and deconvoluted with data analysis software package for Windows from Phoenix Flow Systems.

\section{Western blots}

Total protein extracts from yeast cells were prepared by lysing cells in PEM (Pipes, pH 6.8, $100 \mathrm{mM}$; EGTA $2 \mathrm{mM}$, $\mathrm{MgCl}_{2} 2 \mathrm{mM}$ ) by vigorous vortexing in the presence of glass beads. The cell lysates were centrifuged and the total protein concentrations of the soluble fractions were measured. Samples were supplemented with sample buff-er and prepared for analysis on 7.5\% PAGE. Western blots were performed as described (26) and probed with anti- $\alpha$-tubulin YOL1/34 and anti- $\beta$-tubulin (Boehringer) antibodies in a 1 to 200 and 1 to 500 dilution, respectively. Anti-MHP1 antibody, DIK, was a polyclonal antibody generated against a 20 -mer at position 1180 on the MHP1 sequence and was used in a 1:500 dilution.

\section{RESULTS}

\section{Overexpression of MHP1 hyperstabilizes MTs and in- hibits entry into mitosis}

The overexpression of MHP1 leads to reduced growth and to the formation of long and bundled MTs in interphase cells (14). In order to characterize the phenotype more fully, asynchronously growing Y509 cells (Table I) that overproduce Mhp1p constitutively were analyzed by immunofluorescence with anti-tubulin and DAPI staining and by FACS. Immunofluorescence analysis of representative fields of asynchronously growing cultures of Y509 cells revealed an elevated number of cells in interphase comprising long and bundled MTs. Aliquots of the same cultures were analyzed by flow cytometry and two populations of cells with a DNA content of $2 n$ and $4 n$, respectively, were identified (Fig. 1). Approximately $45 \%$ of the cells had a DNA content of $4 n$ and $55 \%$ a DNA content of $2 n$. Measuring DNA content and cell size of the same sam- 
Table I. Saccharomyces cerevisiae STRAINS USED IN THIS STUDY.

\begin{tabular}{|c|c|c|}
\hline Name & Genotype & Source \\
\hline FLT12 & $\begin{array}{l}\text { a leu2-3 leu2-112 his } 4-519 \text { ade } 1-100 \text { ura3-52 } \\
\mathrm{GAL}^{+}[\mathrm{TUB} 1 \mathrm{TUB} 2 \text { on plasmid pDB68] }\end{array}$ & Bollag et al., 1990. (6) \\
\hline FLT13 & $\begin{array}{l}\text { a leu2-3 leu2-112 his } 4-519 \text { ade } 1-100 \text { ura3-52 } \\
\mathrm{GAL}^{+}[\mathrm{TUB} 1 \mathrm{TUB} 2 \text { on plasmid pDB68] } \\
\text { [MHP1 on plasmid YEP-MHP] }\end{array}$ & This study \\
\hline FLT2 & $\begin{array}{l}\text { a leu2-3 leu } 2-112 \text { his } 4-519 \text { ade } 1-100 \text { ura } 3-52 \\
\mathrm{GAL}^{+} \text {[TUB2 on plasmid pCGT2] }\end{array}$ & Bollag et al., 1990. (6) \\
\hline FLT4 & $\begin{array}{l}\text { a leu2-3 leu2-112 his } 4-519 \text { ade } 1-100 \text { ura3-52 } \\
\mathrm{GAL}^{+}[\mathrm{TUB} 2 \text { on plasmid pCGT2] } \\
\text { [MHP1 on plasmid YEP-MHP] }\end{array}$ & This study \\
\hline FUT1 & $\begin{array}{l}\text { a leu2-3 leu2-112 his4-519 ade1-100 ura3-52 } \\
\mathrm{GAL}^{+} \text {[TUB1 on plasmid pCGT1] }\end{array}$ & Bollag et al., 1990. (6) \\
\hline FUT4 & $\begin{array}{l}\text { a leu2-3 leu2-112 his } 4-519 \text { ade } 1-100 \text { ura3-52 } \\
\mathrm{GAL}^{+} \text {[TUB2 on plasmid pCGT1] } \\
\text { [MHP1 on plasmid YEP-MHP] }\end{array}$ & This study \\
\hline Y501 & $\begin{array}{l}\text { a/ } \alpha \text { ura3 }-52 \text { lys } 2-801_{a} \text { ade } 2-101_{o} \text { trp } 1-\Delta 63 \\
\text { his } 3-\Delta 200 \text { leu } 2-\Delta 1\end{array}$ & Irminger-Finger (unpublished) \\
\hline Y509 & $\begin{array}{l}\text { a/ } \alpha \text { ura3 }-52 \text { lys } 2-801_{a} \text { ade } 2-101_{o} \operatorname{trp} 1-\Delta 63 \\
\text { his } 3-\Delta 200 \text { leu } 2-\Delta 1 \text { [MHP1 on plasmid YEP-MHP] }\end{array}$ & Irminger-Finger et al., 1996 (14) \\
\hline
\end{tabular}

ples demonstrated that the larger cells were $4 n$, the smaller cells 2 n (Fig. 1d). These data suggest that overexpression of MHP1 leads to an inhibition of the passage of cells from G2 into mitosis. Consistent with this interpretation is the observation that the percentage of mitotic cells is less than $0.5 \%$ in an asynchronously growing culture of Y509 cells compared to $2 \%$ in an asynchronously growing culture of the parental wild type Y501 cells.

\section{Mutual compensation of the overexpression of MHP1 and $\alpha$ and $\beta$-tubulin}

To further explore the role of Mhp1p in MT formation, we analyzed the cellular function of MHP1 under conditions of increased tubulin concentrations. Simultaneous overexpression of the $\alpha$ and $\beta$-tubulin genes, TUB1 and TUB2, was established in the yeast strain FLT12 (Table I), overexpressing TUB1 and TUB2 under the control of the induceable GAL10 promoter. FLT12 was transformed with a $2 \mu$ plasmid YEP-MHP containing the entire MHP1 gene, for the constitutive overexpression of MHP1, generating FLT13 cells (Table I). The MT phenotypes of FLT12 and FLT13 cells were analyzed by immunofluorescence at various time points after the induction of tubulin overexpression in the presence of galactose.

In FLT12 cells the excess tubulin was either localized to or around the nucleus or in a few cases in the nucleus and the cytoplasm during the first hours of tubulin overexpression (Fig. 2A), similar to observations made previously (32). This localization was confirmed with anti- $\alpha$ and anti- $\beta$-tubulin antibodies in a maximum of 50 percent of the cells after 4 hours of growth in galactose (Fig. 2A). After more than 5 hours of tubulin overexpression, normal cytoplasmic MTs were visible, and the further increase in tubulin concentration resulted in the formation of long MT fibers. After 10 hours of growth in inducing conditions long MT fibers could be observed in $25 \%$ of the cells (Fig. 2A). In the rest of the cells the tubulin staining was either nuclear or not detectable. The percentage of cells with nuclear tubulin staining decreased at later time points, while the number of cells containing normal cytoplasmic MTs increased. However, the normal cytoplasmic MTs in FLT12 cells were thinner and shorter than in wild type cells. After 17 hours of tubulin overproduction long MT fibers were visible at the cell periphery in $30 \%$ of FLT12 cells, and at later time points only cells with long MT fibers (35\%) or normal cytoplasmic MTs $(65 \%)$ persisted.

In contrast to the results obtained with FLT12 cells, FLT13 cells exhibited normal cytoplasmic MTs after 4 hours of induction of the overexpression of the TUB1 and TUB2 genes (Fig. 2B). The specific MT phenotypes of MHP1 overexpression, as well as of $\alpha$ and $\beta$ tubulin overexpression, were suppressed at that time. FACS profiles of FLT12 and FLT13 cells grown in galactose for ten hours were comparable to the wild type cells Y501 with one single peak for 2n DNA content (data not shown). These results indicate that the over- 


\section{Y501 cells}
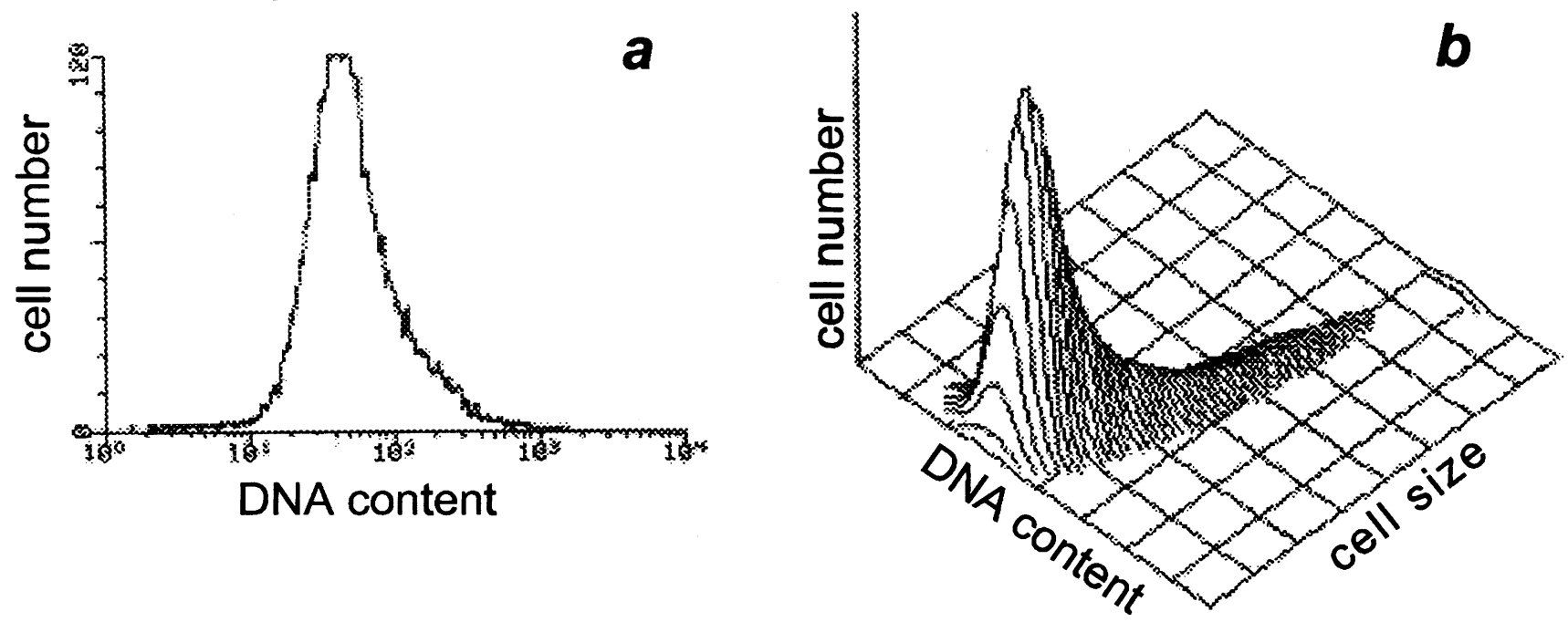

\section{Y509 cells}
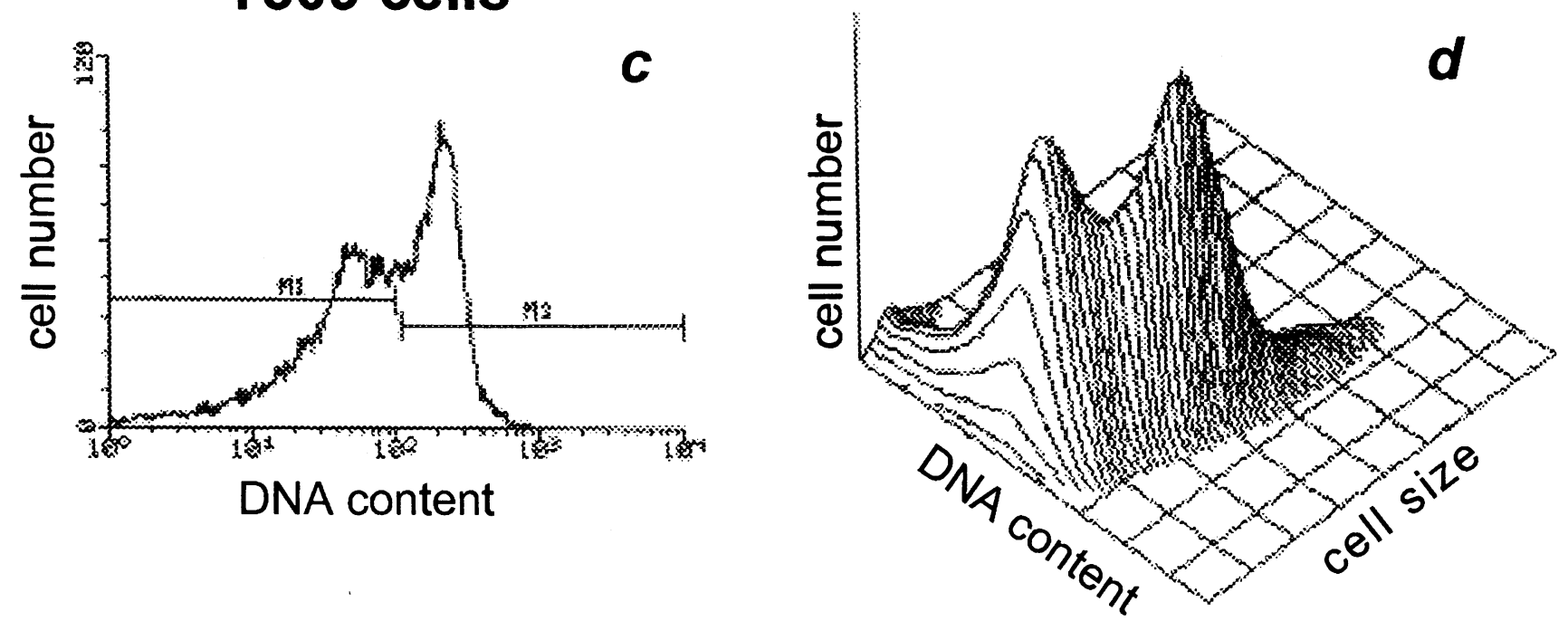

Fig. 1. MHP1 overexpression in wild type cells. FACS analysis of Y501 (wild type) and Y509 cells. Frequency distribution-DNA content histogram of $S$. cerevisiae cells, stained with propidium iodine as described, is presented in $(a)$ and $(c)$, and frequency distribution-DNA content-cell size histogram in $(b)$ and $(d)$. A single fluorescent peak corresponding to the $2 \mathrm{n}$ DNA content is observable in wild type Y501 cells $(a)$, two fluorescent peaks corresponding to the populations of cells with DNA content of $2 \mathrm{n}$ and $4 \mathrm{n}$ can be observed in Y509 cells $(b)$. Regions marked M1 and M2 in $(c)$ were measured and contained $45 \%$ and $55 \%$ of the cells, respectively. Three-dimensional representation of DNA content, cell size, and frequency of cells (cell number) demonstrates that most Y501 cells are of similar size and that Y509 cells (d) consist of two populations of cells. Note that the DNA content of $4 \mathrm{n}$ is correlated with increased cell size in Y509 cells.

expression of MHP1, when accompanied by increased concentrations of $\alpha$ - and $\beta$-tubulin, no longer leads to a cell cycle block during G2, and suggest that the MT hy- per-stabilization by Mhp1p could be compensated by the increase of newly synthesized tubulin.

With increasing time of growth in galactose, the pro- 

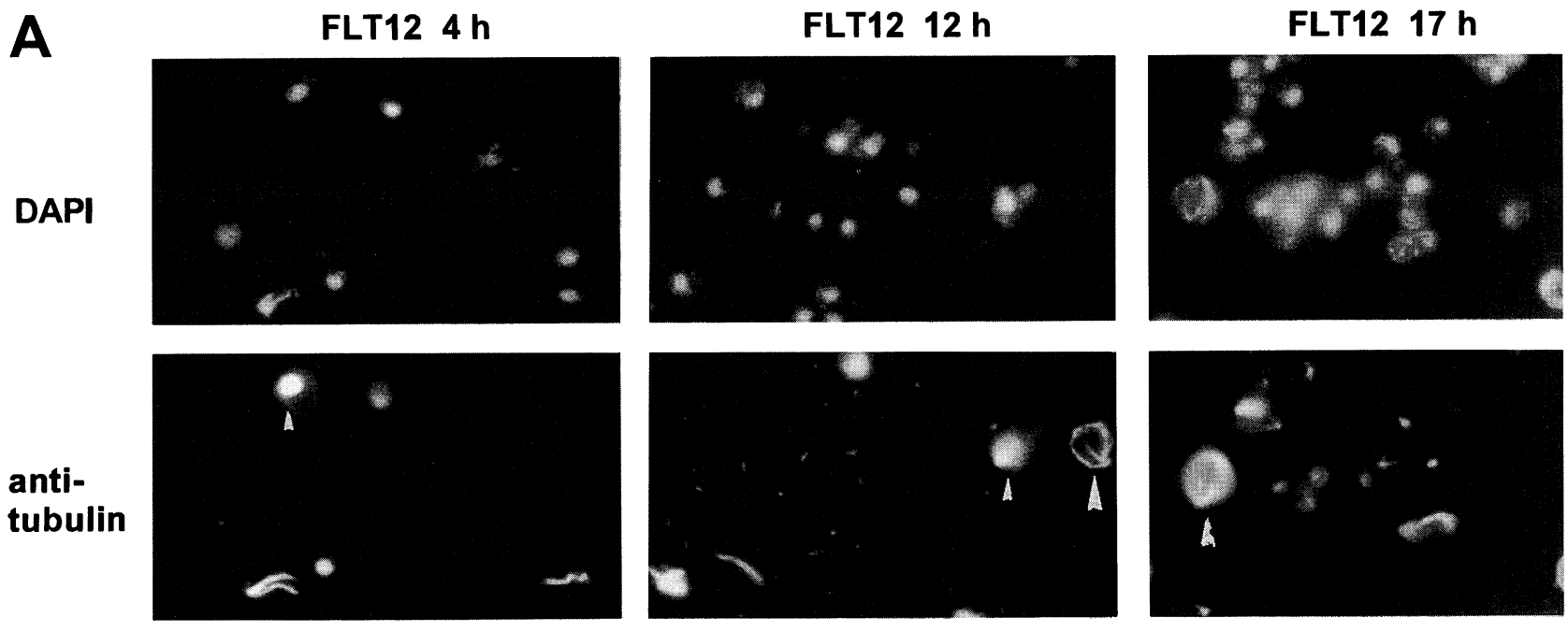

B

FLT13 $4 \mathrm{~h}$
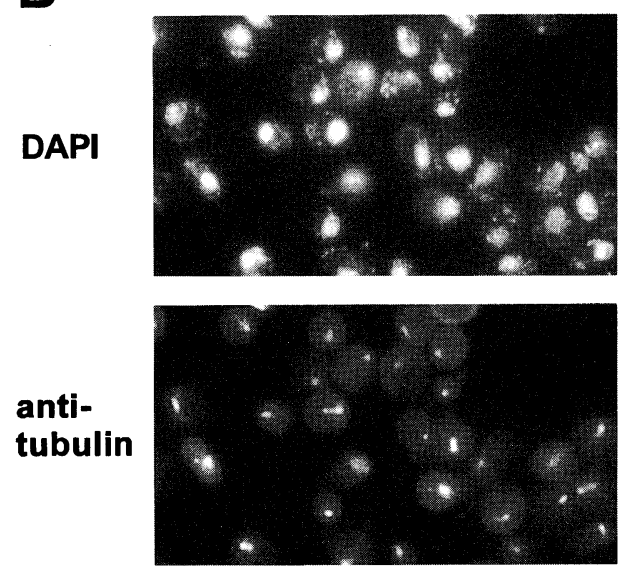

FLT13 $12 \mathrm{~h}$
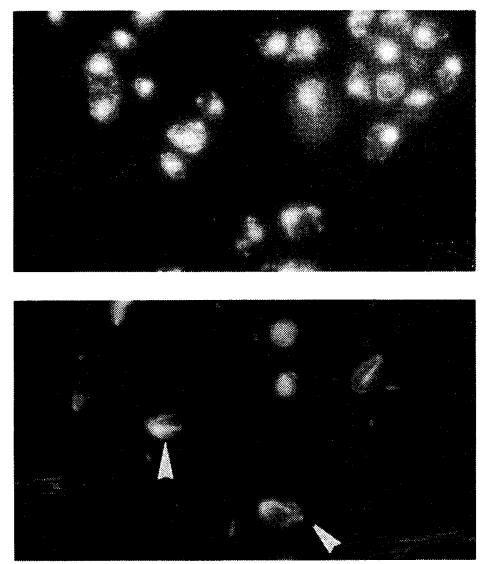

FLT13 $17 \mathrm{~h}$
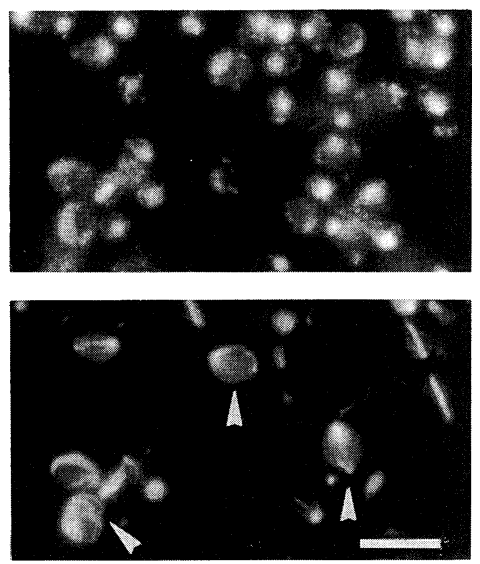

Fig. 2. Simultaneous overexpression of MHP1 and $\alpha$ and $\beta$-tubulin. (A) Immunofluorescence analysis of FLT12 cells, stained with anti- $\alpha$-tubulin antibodies and DAPI, at $4 \mathrm{~h}, 10$, and 17 hours after induction of tubulin overexpression. Note that tubulin accumulates at the nucleus (arrowheads) or fills the entire cell. Long MT fibers are indicated with large arrowheads. (B) Immunofluorescence analysis of FLT13 cells, stained with anti- $\alpha$-tubulin antibodies and DAPI. Long extra MTs are marked with large arrowheads. For the time points of 10 and 17 hours shorter exposure times were applied for FLT13 cells than for FLT12 cells in order to produce equal intensities on the photography, and weak staining of cytoplasmic MTs is not visible under these conditions. Similar images were obtained when anti- $\beta$-tubulin instead of anti- $\alpha$-tubulin antibodies were applied (data not shown). Bar $10 \mu \mathrm{m}$.

duction of $\alpha$ - and $\beta$-tubulin appeared to override the increased production of Mhp1p, and the mutual compensation of the MHP1 and tubulin overexpression could no longer be observed. Long MT fibers, typical for the overexpression of the $\alpha$ and $\beta$-tubulin genes, were formed more frequently when MHP1 was also overexpressed, leading to a steady increase in long MT fibers in individual cells. However, at later time points of $\alpha$ and $\beta$-tubulin overproduction, more and longer MT fibers could be observed in individual FLT13 cells than in FLT 12 cells, and approximately $70 \%$ of FLT13 cells exhibited long MT fibers after 24 hours. The intensity of MT staining was at least three times greater (based on exposure times for the micrographs) in FLT13 cells than in FLT12 cells, indicating that the total tubulin content was higher in individual FLT13 cells than in individual FLT12 cells.

We classified the different types of tubulin staining observed in FLT12 and FLT13 cells as nuclear tubulin localization, normal cytoplasmic MTs, and long MT fibers. The percentages of cells belonging to a class of a specific MT phenotype were plotted for each time point after induction and the number of DAPI-stained cells was defined as the total number of cells (Fig. 3). 

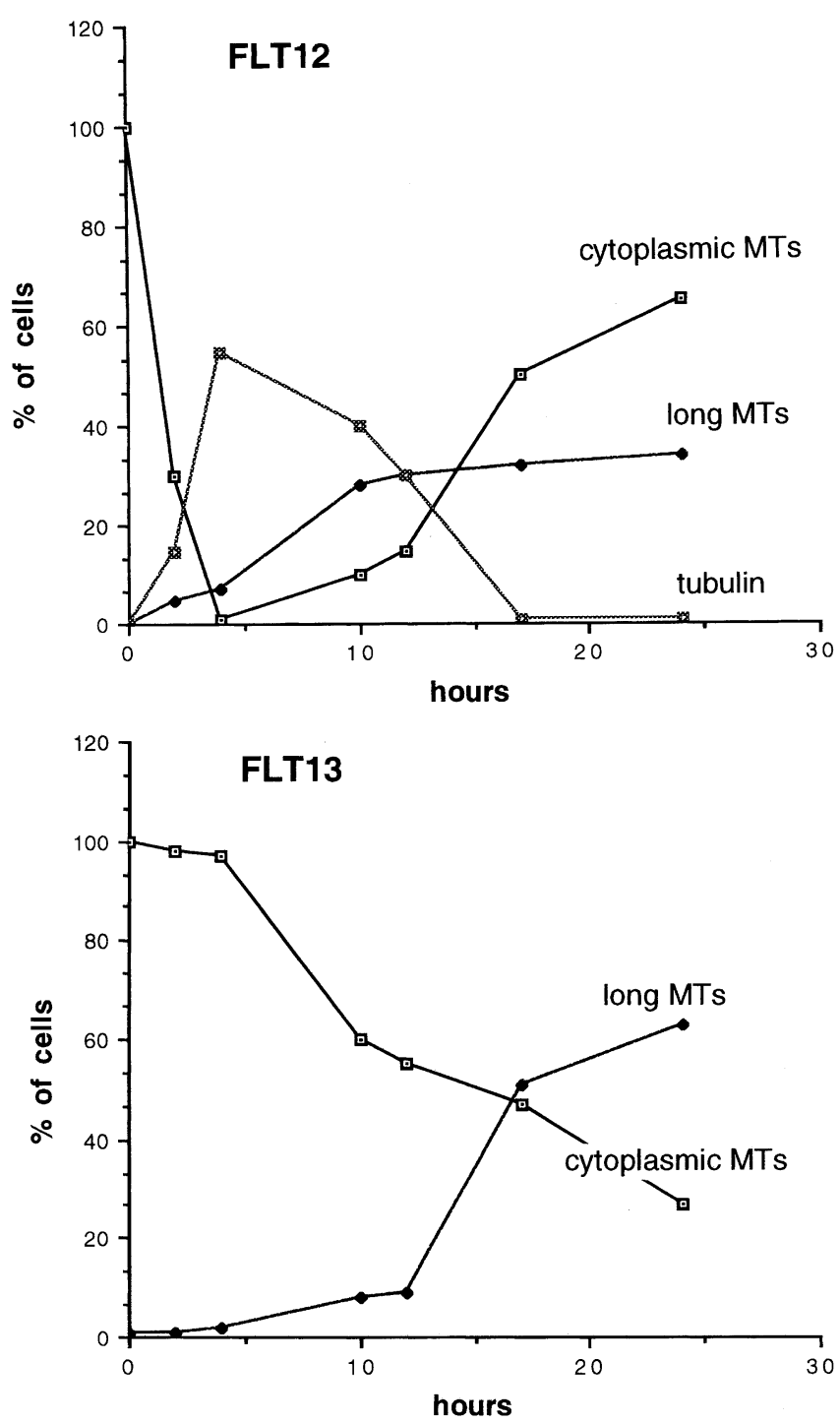

Fig. 3. Comparison of MT phenotypes in FLT12 and FLT13 cells. Cell samples from different time points after induction of tubulin overexpression were analyzed by immunofluorescense as presented in Fig. 2. Five representative fields were analyzed for each time point, and 20 to 60 cells per field were counted and classified as: "cytoplasmic MTs", comparable to normal cytoplasmic MTs, "long MTs", excess MT fi-bers or rings, and "tubulin" intense staining of tubulin in the nucleus or the whole cell, as observed at early time points in FLT12 cells only. Percentages of cells with specific MT-phenotypes were plotted in function of time points after induction of $\alpha$ and $\beta$-tubulin overexpression.

From the comparison of the MT phenotypes in FLT12 and FLT13 cells at different time points after the induction of tubulin overproduction (Fig. 3), it could be concluded that Mhp1p promotes the formation of excess MT fibers and inhibits the depolymerization of cytoplasmic MTs observed in FLT12 cells, presumably due to the increase in tubulin concentration, a phenomenon which has been reported previously $(6,32)$. The formation of normal cytoplasmic MTs and long MT fibers could be observed after a lag phase of 4 hours in a portion of the cells. The co-overexpression of MHP1 and the tubulin genes in FLT13 cells resulted in a slow decrease of the number of cells with cytoplasmic MTs and a steady increase of the number of cells containing long MT fibers. However, at no time the accumulation of tubulin in or at the nucleus was observed in FLT13 cells.

\section{MT stabilization leads to increased total tubulin con- centrations}

Since FLT13 cells contained more frequently long MT fibers than FLT12 cells, when grown in galactose, it was of interest to test whether the total amount of tubulin was also increased in FLT13 cells. The tubulin concen- 
A

a

b
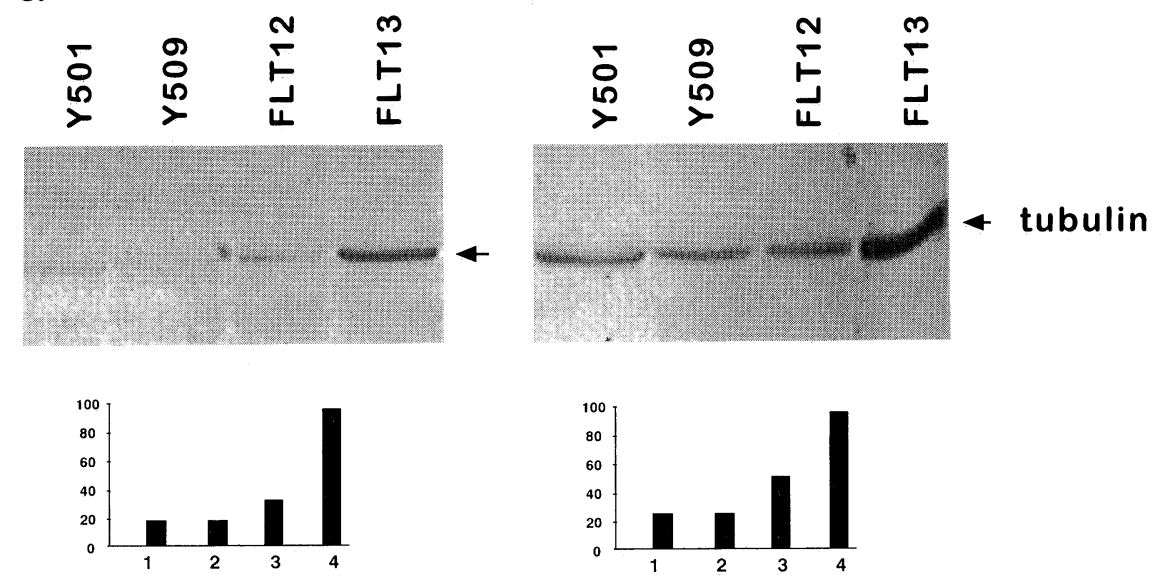

B

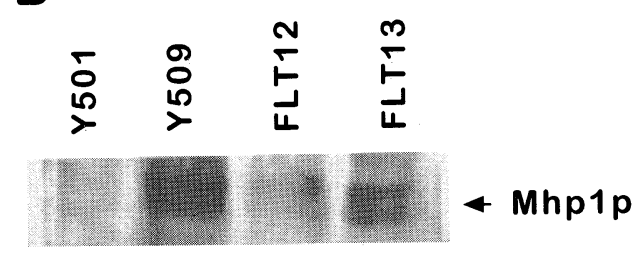

C

a

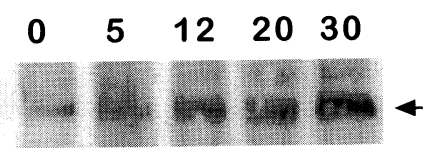

b
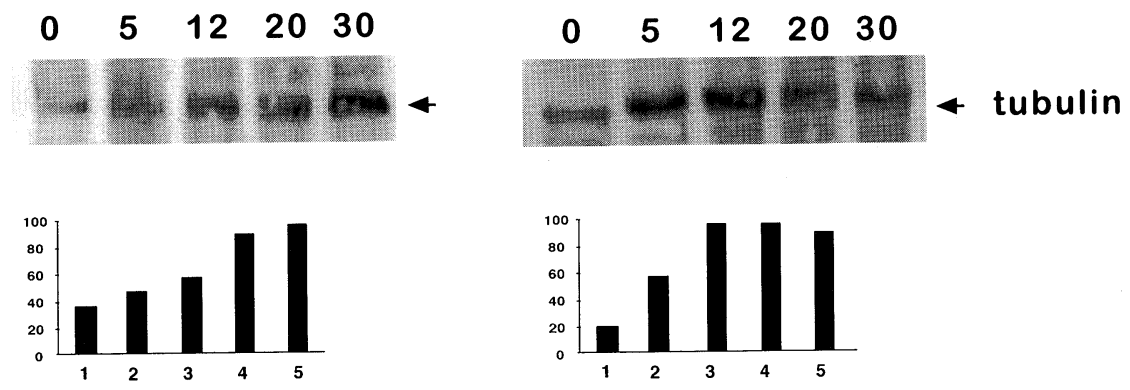

Fig. 4. Tubulin expression in wild type cells and in FLT12 and FLT13 cells. (A) $20 \mu \mathrm{g}$ of protein extracts from Y501 and Y509 cells, and FLT12 and FLT13 cells after 6 hours of growth in galactose, were separated on 7.5\% SDS-PAGE and blotted onto nitrocellulose filters. Western blots were probed with monoclonal anti $\alpha$-tubulin (a) and monoclonal anti- $\beta$-tubulin (b) antibodies. The relative intensities of the reactive bands of the Western blots were measured and blotted below on a relative scale, defining the highest intensities as 100\%. (B) A Western blot of the filter shown in (A) was probed with anti-MHP1 antibodies and visualized by chemiluminescence. The Mhp1p protein, present as a double band of 200 and $180 \mathrm{kD}$, as visualized with anti-MHP1 antibodies, was two-fold to three-fold increased in Y509 and FLT13 cells. (C) Time course of increase in tubulin concentrations in FLT12 and FLT13 cells after induction of tubulin overexpression. Cells were grown in the presence of galactose and prepared for Western blotting at different time points ( 0 to 30 hours) after induction of tubulin overexpression as indicated. Relative tubulin concentrations were monitored by detection with anti- $\alpha$ tubulin antibodies. Tubulin levels for FLT12 cells are presented in (a) and for FLT13 cells in (b). Intensities of reactive bands are blotted on a relative scale below, defining the highest intensities as $100 \%$.

tration in protein extracts from different cell lines were compared on Western blots probed with anti- $\alpha$ - and anti- $\beta$-tubulin antibodies (Fig. 4A). The concentrations of both $\alpha$-and $\beta$-tubulin were twice as high in tubulin overproducing FLT12 cells (after 6 hours of induction) than in Y501 or Y509 cells. However, the tubulin concentrations in FLT13 cells, grown under the same conditions, were at least three-fold increased above wild type levels (Fig. 4A). In comparison, the concentration of Mhp1p was two-fold increased in Y509 and FLT13 
cells that overexpress MHP1, as estimated from the intensities of the Mhp1p double bands recognized with anti-MHP1 antibodies (Fig. 4B). The increase in the tubulin overall concentration, after inducing tubulin overexpression, was faster in FLT13 than in FLT12 cells, leading to the same level of tubulin concentrations after approximately 12 hours of induction in FLT13 cells, as was reached after approximately 24 hours in FLT12 cells (Fig. 4C). This result is consistent with the observations made by immunofluorescence analyses (Fig. 2) and indicates that increased MT polymerization reflects the increased overall tubulin concentration.

\section{Individual overexpression of $\alpha$ or $\beta$-tubulin is not compensated by the overexpression of MHP1}

In order to distinguish whether Mhp1p interacts with MTs by binding to $\alpha$ or $\beta$-tubulin, we tested whether the overexpression of MHP1 could modify the phenotype induced by the overexpression of $\alpha$ or $\beta$-tubulin individually. The formation of filaments composed of $\beta$-tubulin in a small portion of cells surviving the overexpression of $\beta$-tubulin has been described $(6,32)$. It was possible that overproduction of Mhp1p facilitated the formation or stabilization of filaments composed of $\beta$ tubulin in a similar way as it promoted the formation of MTs in FLT13 cells overproducing $\alpha$ - and $\beta$-tubulin. FLT2 cells overexpressing TUB2 under the induceable GAL10 promoter (Table I), were transformed with the $2 \mu$ plasmid YEP-MHP for constitutive overexpression of MHP1, generating FLT4 (Table I). The MT phenotype of FLT4 was indistinguishable from the phenotype of FLT2, when grown in galactose, and no increase in the number of cells containing $\beta$-tubulin filaments could be observed (Fig. 5A). Comparison of DAPI staining and anti-tubulin staining in FLT2 cells revealed that no MTs could be detected in $58 \%$ of the cells (Fig. 5A), presumably as a result of the $\beta$-tubulin overproduction that leading to MT disassembly (32). In contrast, the portion of cells without tubulin staining was less than 4\% in FLT4 cells, indicating that MHP1 overexpression counteracts the reported MT disassembly in $\beta$-tubulin overexpressing cells.

To determine the effect of the simultaneous overexpression of MHP1 and the $\alpha$-tubulin gene, FUT1 cells (Table I) containing the TUB1 gene under the control of the induceable GAL10 promoter on a multicopy plasmid, were transformed with the plasmid YEP-MHP, generating FUT4 cells (Table I). The simultaneous overexpression of MHP1 and $\alpha$-tubulin did not result in a different phenotype than the overexpression of $\alpha$-tubulin by itself (Fig. 5B). In both FUT1 and FUT4 cells normal cytoplasmic MT staining was observed. MTs were weakly stained with anti- $\alpha$-tubulin antibodies in FUT1 and slightly longer and thicker MT fibers could be observed in FUT4 cells (Fig. 5B), consistent with the phenotype of the MHP1 overexpression in cells with wild type tubulin expression. These data suggest that Mhp1p promotes the formation of MTs consisting of $\alpha$ and $\beta$-tubulin dimers, but does not increase the formation of MTs consisting of $\beta$-tubulin polymers.

\section{DISCUSSION}

It has been shown previously that MAPs promote overall MT growth by influencing growing and shrinking rates as well as the frequency of rescue and catastrophe $(10,15,20,28)$. MAP depletion experiments, on the contrary, did not influence the dynamic instability of MTs (5) or produce observable phenotypes (23). We have recently reported that the formation of functional MTs depends on the wild type expression level of MHP1, coding for a MAP in Saccharomyces cerevisiae (14). With the elevated expression of MHP1 the formation of more and longer MT fibers can be observed than with wild type expression levels. This overexpression phenotype could be explained with the role of Mhp1p as a MAP modulating the equilibrium between free tubulin and polymerized MTs by increasing MT stability.

Interestingly, the overexpression of MHP1 also leads to a cell cycle arrest at late G2. This cell cycle defect could be explained with the increased concentration of Mhp1p, resulting in increased MT stability. An increased stability of interphase MTs would counteract the changes of tubulin turnover during the transition from interphase to mitosis, since MTs in interphase cells have longer half-lives than MTs in mitotic cells, as has been demonstrated by photobleaching experiments $(29,30)$. Supposedly, the role of MAPs during mitosis is to favor MT destabilization after their cell cycle dependent phosphorylation. Indeed, ubiquitously expressed MAPs such as MAP4 and XMAP $(1,15,25,31)$ are phosphorylated during mitosis by mitotic kinases such as p34/cdc2. The specificity of MT dynamics in mitotic cells has not been studied in Saccharomyces cerevisiae, but the in vitro dynamics of yeast tubulin are different from brain tubulin (9), and reflect the different requirement of the yeast cell with a lower tubulin content than found in cells from higher eucaryotes, insofar as the addition of MAPs could have an even more drastic effect for yeast tubulin than for brain tubulin polymerization. The overexpression phenotype of MHP1 could therefore be explained based on the premises listed above. It is possible that an increased concentration of Mhp1p hyperstabilizes MTs, and in addition, that the presumed cell cycle dependent phosphorylations or other modifications of Mhp1p are present on an insufficient number of Mhp1p molecules. We conclude that the formation of mitotic MTs is inhibited in the MHP1 overexpressing cells, due to the re- 
A

FLT2
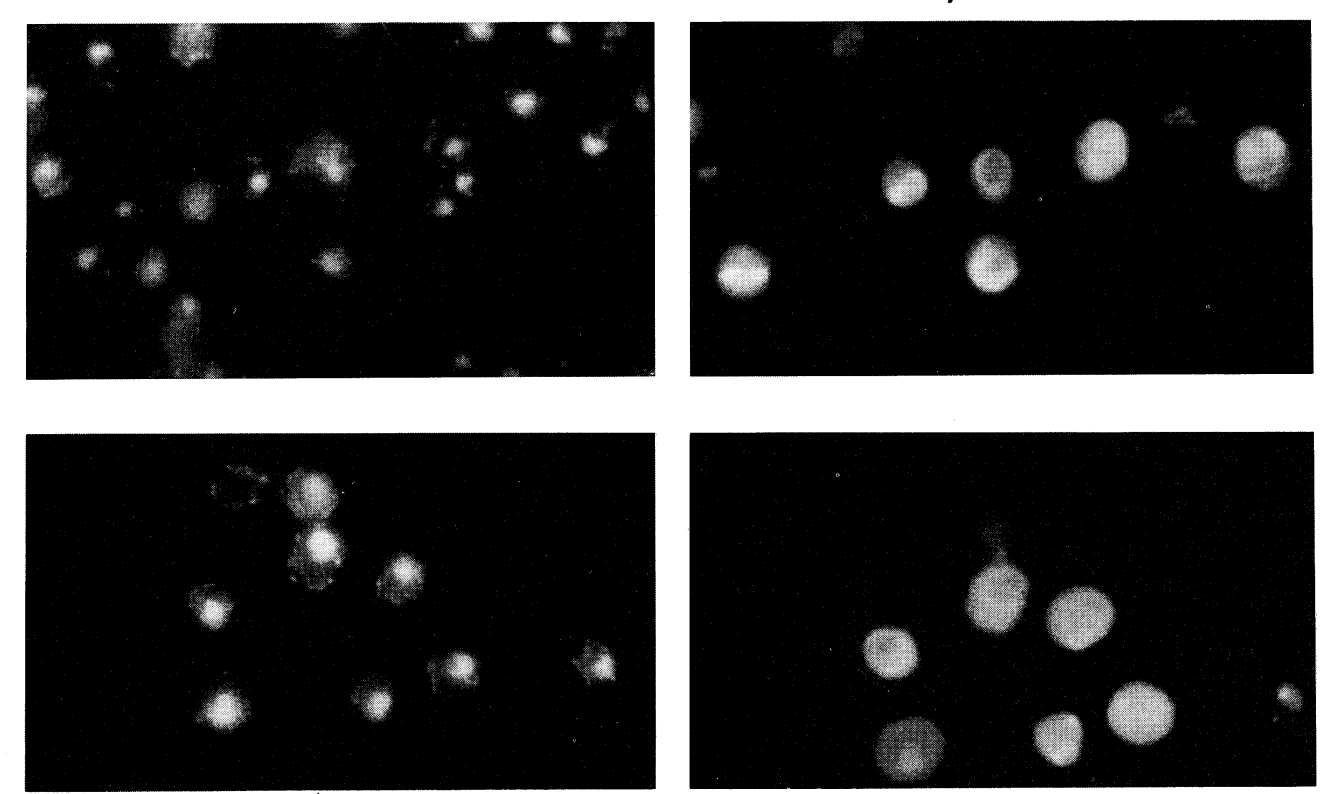

FLT4

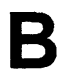

FUT1
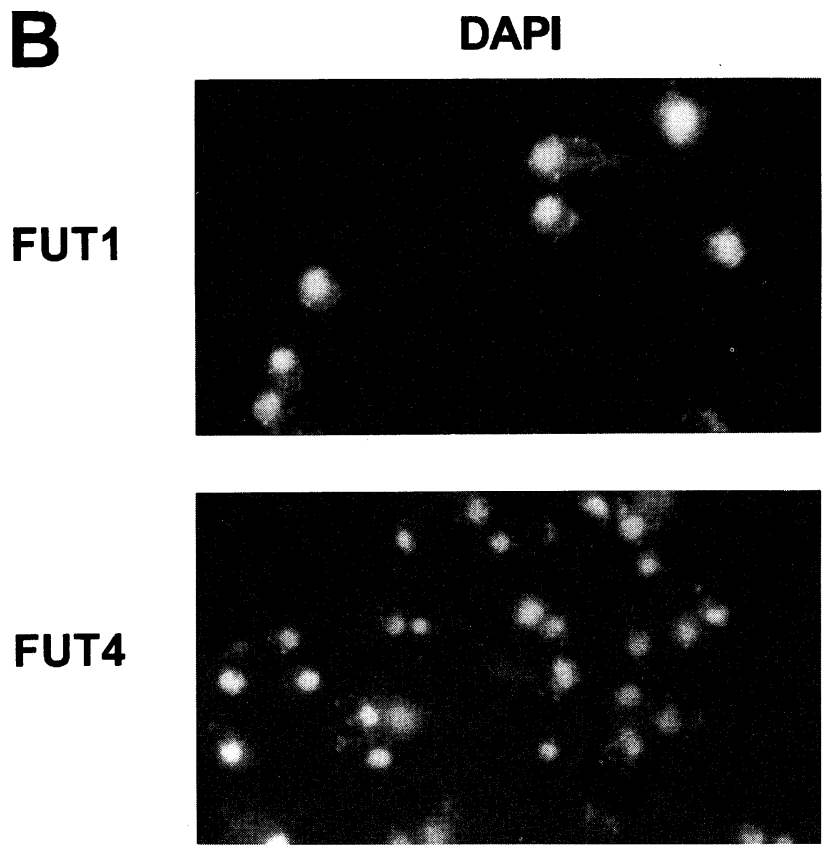

anti- $\beta$-tubulin

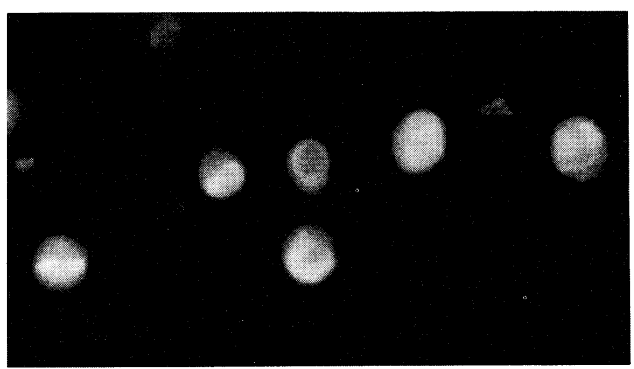

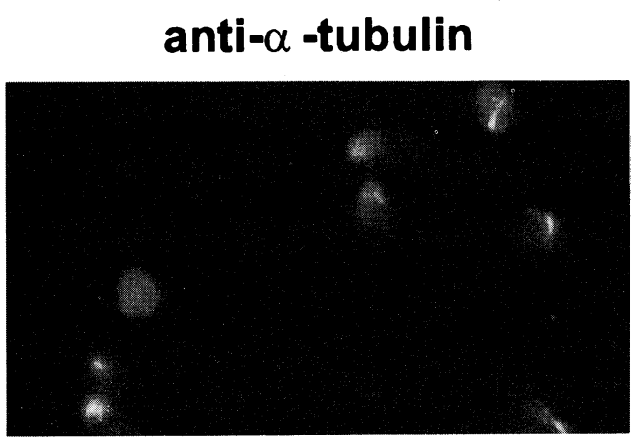

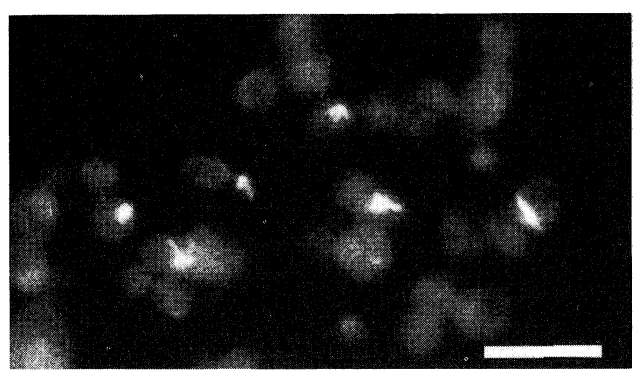

Fig. 5. Simultaneous overexpression of MHP1 and $\alpha$-tubulin or MHP1 and $\beta$-tubulin. (A) Immunofluorescence analysis of FLT2 cells, overexpressing $\beta$-tubulin, and FLT4 cells simultaneously overexpressing MHP1 and $\beta$-tubulin, was performed after 12 hours of $\beta$-tubulin induction. Cells were stained with DAPI and anti- $\beta$-tubulin antibodies. (B) FUT1 cells overexpressing $\alpha$-tubulin and FUT4 cells simultaneously overexpressing MHP1 and $\alpha$-tubulin were analyzed by immunofluorescence microscopy. Expression of $\alpha$-tubulin was induced for 12 hours. Cells were stained with DAPI and anti- $\alpha$-tubulin antibodies. Bar $10 \mu \mathrm{m}$. 
duction of the tubulin turnover rate as a result of the unsatisfactory down-regulation of MT stability.

Co-overexpression of MHP1 and $\alpha$ and $\beta$-tubulin demonstrates that Mhplp promotes the formation of and stabilizes MTs proportional to the elevated tubulin concentrations. At early time points after the induction of $\alpha$ - and $\beta$-tubulin overproduction, the increased amounts of Mhp1p seemed to preserve the normal cytoplasmic MTs in FLT13 (Fig. 2B), while at the same time normal cytoplasmic MTs disappear in FLT12 cells overexpressing only the tubulin genes (Fig. 2A). This difference could be explained with an increased MT stability due to the increase in Mhp1p influencing one or several of the rates governing tubulin turnover. After longer times of induction of tubulin overexpression, long excess MT fibers are formed in a portion of cells. These experiments demonstrate that the elevated expression of MHP1 results in a net increase in polymer formation in vivo and suggest that Mhplp influences one or several parameters that control MT dynamics.

The amount of free tubulin staining is not substantially decreased in FLT13 cells, compared to FLT12 cells. It is possible that increased formation of long MT fibers in FLT13 cells indirectly affects the expression of tubulin, that could be regulated by the concentration of free tubulin. This hypothesis is supported by results obtained on Western blots, that indicate that the comparative tubulin concentrations are lower in cells overexpressing tubulin than in cells overexpressing tubulin and MHP1 (Fig. 4A and B).

MHP1 was co-overexpressed either with $\alpha$ or with $\beta$ tubulin individually, since it was possible that Mhp1p interacted with the MT-like fibers composed of $\beta$-tubulin and facilitated their formation. However, increased levels of Mhp1p did not promote the formation of fibers composed of $\beta$-tubulin and no differences in the MT phenotypes could be observed in cells overexpressing $\beta$-tubulin (FLT2), or $\beta$-tubulin and MHP1 (FLT4), neither when stained with anti- $\beta$-tubulin nor with anti$\alpha$-tubulin antibodies. However, Mhp1p seems to increase the stability of preexisting MTs, since the number of cells with disassembled MTs was reduced in FLT4 cells (Fig. 5A), consistent with a reduced turnover rate and reduced dynamics of preexisting MTs. Similarly no phenotypic changes were observed when MHP1 and $\alpha$-tubulin were overexpressed simultaneously. It is therefore conclusive that Mhp1p does not interact with $\alpha$ - or $\beta$-tubulin, but drives polymer formation by binding to preformed MTs.

The exact mechanism how MAP4 type proteins regulate MT dynamics in higher eucaryotes is not currently known, partly because of the lack of mutations and partly because of the existence of redundant MAP proteins with specific but overlapping functions. Different experiments aimed at the analysis of the in vivo func- tion of MAPs have been performed in mammalian cells and have led to interesting observations $(4,24)$, or to the description of specific functions for individual MAPs (3). None of the MAPs tested, however, could be strictly assigned with a role in MT assembly in vivo, which could be due to the fact that in mammalian cells some functions of a specific MAP might be concealed by overlapping functions of other MAPs. The presented assay in Saccharomyces cerevisiae can be exploit to investigate the role of MAPs in MT assembly in vivo. Although MT dynamics in yeast are subjected to different rates (growth and shrinking, rescue and catastrophy) than MT dynamics in higher eucaryotes, the phenotypes observed with the overexpression of the yeast MAP MHP1, can be explained by adopting this general scenario. Two reasons make it likely that the impact of MAPs on MT dynamics might be greater in yeast than in higher eucaryotic cells: Firstly, the tubulin concentrations in yeast cells are approximately ten times lower than in mammalian cells; Secondly, MAPs in Saccharomyces cerevisiae are presumably less redundant than MAPs in other organism, as was demonstrated for the Drosophila 205K MAP the only MAP were genetic manipulations were possible (27). Future research will focus on the analysis of specific MHP1 mutants that lack their ability to promote MT formation in wild type yeast cells and in cells with increased tubulin concentrations. This approach should lead to the identification of phosphorylation sites on Mhp1p that are essential for the progression into mitosis. Other possible applications will be testing the function of MAPs from higher eucaryotes in MT assembly in vivo, in the background of the tubulin overproducing FLT12 cells.

Acknowledgments. We are grateful to D. Wohlwend for assistance with the ctyometry measurements and Dr. J. Cox for critical reading of the manuscript. We thank Dr. S.J. Edelstein for support and useful suggestions. This work was supported by the Swiss National Science Foundation (grant to S.J. Edelstein).

\section{REFERENCES}

1. Andersen, S.S., Buendia, B., Dominguez, J.E., SAwyer, A., and KARSENTI, E. 1994. Effect on microtubule dynamics of XMAP230, a microtubule-associated protein present in Xenopus laevis eggs and dividing cells. J. Cell Biol., 127: 1289-1299.

2. ArCher, J.E., VeGA, L.R., and Solomon, F. 1995. Rb12p, a yeast protein that binds to $\beta$-tubulin and participates in microtubule function in vivo. Cell, 82: 425-434.

3. BaAR, P.W., Pienkowski, T.P., and KosiK, K.S. 1991. Processes induced by tau expression in Sf9 cells have an axon like microtubule organization. J. Cell Biol., 115: 1333-1344.

4. Barlow, S., Gonzales-Garay, M.L., West, R.R., Olmsted, J.B., and CABRAL, F. 1994. Stable expression of heterologous microtubule-associated proteins (MAPs) in Chinese hamster ovary cells: evidence for differing roles of MAPs in microtu- 
bule organization. J. Cell Biol., 126: 1017-1029.

5. Billger, M.A., BhatacharJee, G., and Williams, Jr. R.C. 1996. Dynamic instability of microtubules assembled from microtubule-associated protein-free tubulin: neither variability of growth and shortening rates nor "rescue" requires microtubule-associated proteins. Biochemistry, 35: 13656-13663.

6. Bollag, M.D., Tornare, I., Stalder, R., Paunier Doret, A.-M., Rozycki, M.D., and Edelstein, S.J. 1990. Overexpression of tubulin in yeast: differences in subunit association. Eur. J. Cell Biol., 51: 295-302.

7. Burke, D., Gasdaska, P., and Hartwell, L. 1989. Dominant effects of tubulin overexpression in Saccharomyces cerevisiae. Mol. Cell Biol., 9: 1049-1059.

8. CASIMERIS, L. 1993. Regulation of microtubule dynamic instability. Cell Motil. Cytoskeleton, 26: 275-281.

9. Davis, A., Sage, C.R., Wilson, L., and Farrell, K.W. 1993. Purification and biochemical characterization of tubulin from the budding yeast Saccharomyces cerevisiae. Biochemistry, 32: $8823-8835$.

10. Drechsel, D.N., Hyman, A.A., CobB, M.H., and Kirschner, M.W. 1992. Modulation of dynamic instability of tubulin assembly by the microtubule-associated protein tau. Mol. Biol. Cell, 3: 1141-1154.

11. Drubin, D.G. and KirSChNeR, M.W. 1986. Tau protein function in living cells. J. Cell Biol., 103: 2739-2746.

12. Gamblin, T.C., Nachmanoff, S.H., and Williams, Jr. R.C. 1996. Recombinant microtubule-associated protein $2 \mathrm{c}$ reduces the dynamic instability of individual microtubules. Biochemistry, 35: 12576-12586.

13. Hirokawa, N. 1994. Microtubule organization and dynamics dependent on microtubule-associated proteins. Curr. Opin. Cell Biol., 6: 74-81.

14. Irminger-Finger, I., Hurt, E., RoebucK, A., Collart, M.A., and EDELSTEIN, S.J. 1996. MHP1, an essential gene in Saccharomyces cerevisiae required for microtubule function. $J$. Cell Biol., 135: 1323-1339.

15. Iтон, T.J. and Hotani, H. 1994. Microtubule-stabilizing activity of microtubule-associated proteins (MAPs) is due to increase in frequency of rescue in dynamic instability: shortening length decreases with binding of MAPs onto microtubules. Cell Struct. Funct., 19: 279-290.

16. Izant, J.G., Weatherbee, J.A., and McIntosh, J.R. 1983. A microtubule-associated protein antigen unique to mitotic spindle microtubules in PtK1 cells. J. Cell Biol., 96: 424-434.

17. Katz, W., Weinstein, B., and Solomon, F. 1990. Regulation of tubulin levels and microtubule assembly in Saccharomyces cerevisiae: consequences of altered tubulin gene copy number in yeast. Mol. Cell Biol., 10: 2730-2736.

18. Kilmartin, J. and Adams, A. 1984. Structural rearrangements of tubulin and actin during the cell cycle of the yeast Saccharomyces. J. Cell Biol., 98: 922-933.

19. Kilmartin, J.V., Wright, B., and Milstein, C. 1982. Rat monoclonal antibodies derived by using a new nonsecreting rat cell line. J. Cell Biol., 93: 576-582.
20. Kowalski, R.J. and Witliams, R.C. 1993. Microtubule-associated protein 2 alters the dynamic properties of microtubule assembly and disassembly. J. Biol. Chem., 268: 9847-9855.

21. LEE, G. and RocK, S.L. 1992. Expression of tau protein in non-neuronal cells: microtubule binding and stabilization. $J$. Cell Sci., 101: 227-237.

22. MCNally, F.J. 1996. Modulation of microtubule dynamics during the cell cycle. Curr. Opin. Cell Biol., 8: 23-29.

23. Wang, X.M., Peloquin, J.G., Zhai, Y., and Borisy, G.G. 1996. Removal of MAP4 from microtubules in vivo produces no observable phenotype at the cellular level. J. Cell Biol., 132: 345-357.

24. Olson, K.R., McIntosh, J.R., and Olmsted, J.B. 1995. Analysis of MAP4 function in living cells using green fluorescent protein (GFP) chimeras. J. Cell Biol., 130: 639-650.

25. Ookata, K., Hisanaga, S., Bulinski, J.C., Murofushi, H., Aizawa, H., Itoh, T.J., Hotani, H., OKumura, Е., TaChibana, K., and Kishimoto, T. 1995. Cyclin B interaction with microtubule-associated protein 4 (MAP4) targets $\mathrm{p} 34^{\text {cdc2 }} \mathrm{ki}$ nase to microtubules and is a potential regulator of M-phase microtubule dynamics. J. Cell Biol., 128: 849-862.

26. Ortega Perez, R., Irminger-Finger, I., Arrighi, J.F., CaPelli, N., van Tuinen, D., and Turian, G. 1994. Identification and partial purification of calmodulin-binding microtubule-associated proteins from Neurospora crassa. Eur. J. Biochem., 226: 303-310.

27. Pereira, A., Doshen, J., Tanaka, E., and Goldstein, L.S.B. 1992. Genetic analysis of a Drosophila microtubule-associated protein. J. Cell Biol., 116: 377-383.

28. Pryner, N.K., Walker, R.A., Skeen, V.B., Bourns, B.D., SoboEIro, M.F., and SAlmon, E.D. 1992. Brain microtubule-associated proteins modulate microtubule dynamic instability in vitro. Real time observations using video microscopy. $J$. Cell Sci., 103: 965-976.

29. Salmon, E.D., Leslie, R.J., Karow, W.M., Macintosh, J.R., and SAXton, W.M. 1984. Spindle microtubule dynamics in sea urchin embryos: analysis using fluorescence labeled tubulin and measurements of fluorescence distribution after laser bleaching. J. Cell Biol., 99: 2165-2174.

30. Saxton, W.M., Stemple, D.L., Leslie, R.J., SAlmon, E.D., Zavotink, M., and McIntosh, J.R. 1984. Tubulin dynamics in cultured mammalian cells. J. Cell Biol., 99: 2175-2186.

31. Vandré, D.D., Centonze, V.E., Peloquin, J., Tombes, R.M., and BorisY, G.G. 1991. Proteins of the mammalian mitotic spindle: phosphorylation/dephosphorylation of MAP-4 during mitosis. J. Cell Sci., 98: 577-588.

32. Weinstein, B. and Solomon, F. 1990. Phenotypic consequences of tubulin overproduction in Saccharomyces cerevisiae: Differences between alpha-tubulin and beta-tubulin. Mol. Cell Biol., 10: 5295-5304.

(Received for publication, November 18, 1997 and in revised form, June 26, 1998) 